\title{
AC 2011-282: USING PORTFOLIOS TO TELL THE DESIGN BACKSTORY
}

Josh Tenenberg, University of Washington, Tacoma

Josh Tenenberg is a Professor in Computing and Software Systems at the University of Washington, Tacoma. He employs the behavioral and social sciences in analysing and designing the relationship between people and technologies. He is Co-Editor-in-Chief of the ACM Transactions on Computing Education.

(C)American Society for Engineering Education, 2011 


\section{Using portfolios to tell the design backstory}

This paper is about how I have had students use portfolios in carrying out design project work. There is nothing novel about portfolios, or the student use of them; they have been used extensively in evaluating teaching ${ }^{17}$, student learning ${ }^{1,24}$, and for professional development ${ }^{7,14,15}$. The novelty here is in the purpose for which I require students to use portfolios in an Interaction Design course: to tell the backstory of their design projects. Kees Dorst ${ }^{9}$, the design educator, researcher, and practitioner, emphasizes how this backstory characterizes expert design work: "When you design, you are actually creating two things in parallel: the design itself and the story behind it. This story consists of all the choices you have made during your design project and the arguments that you used in making them. It is the justification of the design, which explains why the design is constructed just the way it is."

This paper is my portfolio-as-backstory about how I came to use these portfolios for a design course in this manner. I deliberately use a personal and informal voice rather than a distant and academic one so as to illustrate the portfolio form. That is, this paper itself serves as a model for the kind of portfolio that I ask students to produce. I tell the backstory, along with a frontstory of how I have students use portfolios, and link these to the theoretical grounding on which this use is based. In addition, I provide artifacts drawn from my work on this course and that of my students to illustrate how portfolios serve the dual purposes of mediating professional and academic practices outside the classroom while also mediating interpersonal interaction inside the classroom. In addition, portfolios document student work, help students reflect upon their own creative process, and make this process visible to other students and the instructor.

\section{My backstory: what does an academic add to practice?}

This story starts with a novel teaching model that I developed for collaborating with industry professionals in the classroom, what I call Industry Fellows. Industry Fellows involves a college professor and a practicing professional who plan and teach a course together so as to exploit what each does best. During winter 2009, I collaborated with Adam Barker, a User Experience Designer at Google, to teach a course at the University of Washington, Tacoma (UWT) in Interaction Design ${ }^{12}$. Adam came to my class once each week, narrating to students nifty things that he had worked on as a designer, and helping me to critique student project work. I did all of the heavy lifting — writing the syllabus and assignments, grading, dealing with group problems. These are things that Adam had neither the interest, time, expertise, or legal sanction to do. There was thus a clear division of labor. I structured classroom situations so as to increase interaction between Adam and the students, using student project work as a point of focus. And things worked rather well; in short, Adam was a star. But this paper is not about Industry Fellows, which is described elsewhere ${ }^{20,21,22,27}$.

Rather, this paper is about my response to two problems that emerged. In order to understand them, and how and why I responded as I did, I provide additional context about the course. Interaction Design involves "designing interactive products to support the way people 
communicate and interact in their everyday and working lives [p8]" ${ }^{26}$. The learning outcomes for the course are for students to:

1. carry out user inquiry to understand human needs in particular contexts;

2. construct design sketches and prototypes to manifest design ideas;

3. construct narratives of use so as to communicate use in context;

4. reflect on the design process to make learning visible;

5. carry out a usability studies to get feedback on the user experience.

6. work effectively in teams to carry out much of the above work;

A typical Interaction Design course often requires students to design particular digital artifacts (such as sketches or prototypes), or to engage in user research (such as usability studies or user interviews) that are used for assessing the learning outcomes.

The course that I offered in winter 2009 involved a term-length design project completed by groups of three to five students. Here is the design brief given to students "You will design a website or computer application for a specific user population that significantly improves on what currently exists (the status quo), possibly introducing new and innovative functionality. This website/application must address observed breakdowns and/or unmet needs and goals of your target population in their use of the status quo software." Students employed a usercentered design process ${ }^{16}$, doing observations and interviews with users ${ }^{25}$, sketching design ideas $^{5}$, constructing prototypes ${ }^{13}$, and doing usability testing ${ }^{10}$. Their work was handed-in in three milestones roughly three weeks apart, where each milestone included an in-class presentation and a milestone report. Artifact 1 below describes the report requirements for the second milestone, and constitutes the first artifact of this paper.

1. Executive Summary: Provide a one-page "executive summary" of your milestone. Make sure to include a description of your population, the problem that you have identified, and a description of how your design solves this problem.

2. Additional user inquiry: If you do additional data collection, analysis, or any other activity for refining your population and/or identifying their needs, goals, and constraints; or, if you do any other activity to address the concerns that we indicated on our written response to milestone 1 , please include a writeup of this.

3. Divergent design ideas: Describe and illustrate the set of different design ideas in the form in which your group (or individuals in the group) expressed them during this milestone. These will likely be drawings on paper or whiteboard, but also might include screenshots or photos of partially developed sketches/prototypes. There should be several!

4. Choice rationale: Provide a rationale for your choice of the design idea(s) that you converged on for prototyping. That is, given the set of ideas that you considered, why did you choose these ideas for further development?

5. Novelty: Is it novel? If not novel, how does it differ from what currently exists, and how is it better?

6. Appropriate to user needs: Make sure to indicate how this design meets the key goal(s) that you identified among your population. 
7. Sketch/Prototype: A finished sketch/prototype that is ready to usability test. Provide a video capture of your sketch/prototype in action (not a usability test, just a "proof of concept" demonstration). You might want to use video screen capture software, such as TechSmith Camtasia or Morae. Their website allows you to download functional 30-day trial software.

8. Usability Test Preparation: A copy of each of the usability test documents that indicate the design of the test (what will be tested), the tasks that will be undertaken and a script for guiding the user through the tasks, a user screening sheet, a user informed consent form, and a post-test interview guide.

9. Usability Test Schedule: A brief description of the people (not less than three) who have agreed to undertake the usability tests and the times when you have scheduled the tests during the weeks of Feb 24 and March 3.

Artifact 1: Milestone report requirements

Now to the first problem: students hated doing these reports. Not only were they time consuming, but they saw no value in writing them. Even worse, they saw these reports as detracting from the important work of doing design. This fact came out at the end of the course, when Adam and I debriefed the class, asking a number of questions about how the course went. To make matters worse yet, Adam saw no value in these milestone reports. Adam learned everything that he needed to know about student learning from their presentations and the ensuing discussion associated with each project milestone. As a practitioner, he does not have the time to write long documents that no one will read about the designs that he creates. And he certainly did not want to read the reports that students handed in for each milestone! Truth be told, most of the reports that I read fell short of my expectations, so I didn't really like them either. In these reports, students were not providing sufficient connection between the user data that they were collecting and the design iterations that they were creating, one of my goals for having these reports. And I was not getting much insight into the reasons why they were making their important design choices. It was clear that I needed to give up these reports, but I wanted to replace them with something else. I felt that the reports (or something like them) had a role to play in the course but I was as yet unable to make this clear either to myself or the students.

Solving the problem of replacing these reports was connected to a second, interrelated problem that I faced. This second problem nagged at me in the background during the quarter I taught with Adam, though I mostly ignored it. The problem was that I was unsure of my new role in the classroom when teaching with the industry fellow. By role I am not talking about my formal title, but rather about how I now functioned (or should be functioning) in the classroom given Adam's presence. That is, the industry fellow has considerably more domain expertise. But more than this, Adam enacted this expertise dynamically, when encountering the students and their work, reflective of the ways in which he might apprentice junior colleagues new to his work group. His discussions were saturated with a sense of design wisdom derived from having to make pragmatic tradeoffs in real-world settings, something of which I was simply incapable. It would be too strong to say that I had a crisis of confidence, but there were days in which I did wonder a bit what value $I$ added. That Adam would be able to engage students in authentic practice is not surprising, since interaction design is his day job, whereas teaching, research, and service 
dominate my time as a professional academic. My contribution necessarily needed to be different than Adam's - we simply had different (though overlapping) kinds of expertise, and worked under different (though overlapping) constraints and goals. But I had not yet articulated the way in which I needed to enact my expertise so as to complement Adam's.

To summarize the state of play, I had one problem concerning wanting to replace milestone reports with something else without being sure quite what, and another problem in which I was wrestling with my new role in working with an industry practitioner.

Fast forward one year when this sense of not yet being comfortable in this new role resurfaced, much more strongly. This time my industry fellow was not Adam - he had changed jobs and moved out of the area-but Adam's colleague at Google, Jake Knapp. This uncomfortable feeling emerged precisely at the moment in which I was putting together the course materials in preparation for the new term. Although I was happy to cut the milestone reports, I sensed that something was missing, that I needed to exploit the characteristics of the university context and the kind of learning that it can bring about. I felt that I should be fostering a kind of learning that is distinguished from the learning-in-practice common to apprenticing on the job that my industry fellow was able to foster.

\section{Sources of inspiration drawn from research}

At this point, I drew inspiration from three sources. The first is from the work of Donald Schön, who studied the development of practice among professionals in a variety of disciplines, especially design ${ }^{18}$. From empirical studies of design professionals, he noted important characteristics of skilled practice. Rather than mechanically applying general principles and laws to problems of practice, what he called technical rationality, he noted that practitioners routinely "think on their feet" in response to the complexity of everyday settings, what he called knowingin-action. In addition, practitioners critically reflect upon their performance afterward. "We reflect on action, thinking back on what we have done in order to discover how our knowing-in-

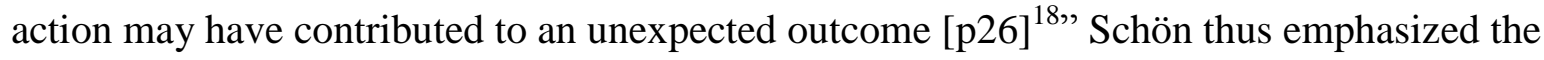
importance of using deliberate reasoning to interrogate one's own enacted practice.

The second inspiration is from a book chapter by Ann Brown and colleagues concerned with the distribution of knowledge and skill in a K-12 classroom ${ }^{2}$. In this chapter, they inquire about the teacher's role in the classroom. They remark that unlike practitioners (or university professors) in a profession such as engineering, K-12 teachers do not have deep domain knowledge. Rather than apprenticing students into a particular practice, K-12 teachers have a different role. "We argue that schools should be communities where students learn to learn. In this setting teachers should be models of intentional learning and self-motivated scholarship, both individual and collaborative [p190]."

It may seem odd that I find inspiration from this comment, given that an important purpose of a university education in engineering is that students do learn deep domain knowledge. But this is not sufficient for a life of professional practice, in which the methods, technologies, and 
surrounding social context of engineering work is continuously changing; students must leave the university with the ability to learn how to learn. Like the K-12 teacher, the university teacher must also foster this ability, but do so within the context of teaching engineering practice. By combining Ann Brown's insights with those of Schön, I suggest that cultivating reflective practice in our students is a key way in which students can learn how to learn.

The final source of inspiration comes from a book by William Sullivan and Matthew Rosen, scholars from Carnegie Foundation for the Advancement of Teaching ${ }^{19}$. This book, represents the culmination of a Carnegie initiative called "Preparation for the Professions Program", and is concerned with what the liberal arts offers to students in practice-based disciplines such as engineering. In the forward, one of the principals in the project, an accomplished professor of Education, confesses his "crisis of confidence" near the end of his career when he saw that many of his students were not enacting the principles that he taught in his courses; they were not moving theory into their practice as new teachers. He inquired how he could better help them to connect their academic work to their practice. He and his co-author spend much of the book describing how the liberal arts curriculum might be structured so as to do so. In this regard, they view the liberal arts as cultivating the life of the mind, critical reason, and reflection. But they argue that in educating students for the professions (such as engineering and design), these habits of inquiry need to be used not just in the abstract (as they might in many courses in the Humanities) but applied to problems of practice. "So a life of the mind for practice means the cultivation of reflection and criticism, such as advocates of critical thinking promote, but not for the sake of reflecting and criticizing alone. Rather, the point of such cultivation is that students must learn to deliberate about their possibilities for a life well lived, including their responsibility to contribute to the life of their times ... the focus is on thinking that is oriented toward decision and action $[\mathrm{pxvi}]^{19}$."

To summarize, Schön argues for using reflection on action as a means to improve practice. Adding Brown's insight to this suggests that reflection on action can be used to learn how to learn. And William and Sullivan's insight suggests that this reflection on practice needs to involve deep critical reason.

By combining these sources of inspiration, I finally recognized that it was this kind of reflection on practice that I had hoped the milestone reports would foster for my students. The problem, it seems, was not in the purpose of the milestone reports, but in their form. Having a clear sense of purpose, I could now seek a different representational form.

\section{The portfolio as a representation of practice}

It was my past use of portfolios on another project ${ }^{23,8,11}$ that led me to consider them as a possible way to achieve the kinds of reflection on practice that I mention above. Portfolios are a well known form, used professionally in design and art $^{7,14,15}$ as well as in higher education ${ }^{6,17}$. They include not only a set of artifacts that represent the creative abilities of their creator, but they also include a narrative that describes the meaning and significance of the artifacts toward achieving some goal or purpose. Despite their differences of use, all portfolios are constructed 
under constraints (e.g. of space and medium), designed to serve a particular purpose (e.g. for obtaining a job, or demonstrating learning), and require that their creator exercise deliberate choice in selecting the artifacts to include.

I thought that having students use this representational form would well serve my purposes of having students critically reflect on their process of design. Artifact 2 (below) shows my new requirements for the portfolio that now replaced the milestone report: students were required to include 6 artifacts (thus requiring deliberate selection), and a short narrative telling the backstory of their design. This form thus serves the same purpose as the milestone report but is much lighter weight. In addition, the portfolio form is one that is as much from professional practice as it is from academics, thus serving to bridge these worlds. It is compact, powerful, and authentic.

In adapting portfolios to suit my purposes, I emphasized the importance of story, which was one of the themes that was interwoven throughout the term. In this course, story appears first in the writings of Bill Buxton whose recent book Sketching user experiences ${ }^{5}$ served as one of the course texts. Buxton describes and demonstrates how designers can represent stories of envisioned use of to-be-designed artifacts. That is, designers should not simply provide a technical view of a new digital device, but additionally should uses sketches, prototypes, storyboards, videos, and other media to show how such devices, if implemented and used, affect human and social life.

This envisioning use of story was reinforced by Jake (my industry fellow), who repeatedly told students that one of the most important jobs of the designer is to "tell the story" of what they are designing so that others can envision it. This not only helps to create a shared vision among the designers, but is crucial for clients and/or upper management in continuing to fund this project throughout its lifecycle.

And finally, I emphasized to students the importance of the backstory of the design rationale. This story parallels the envisioning story, and it is required so as to convince others that their design meets the needs of the people for whom they are designing. Portfolios were thus not an alien form, as the academic essay of the milestone reports were, but rather a representation drawn from professional practice to unify the different senses of story that ran throughout the course.

Each deliverable will include a design portfolio that consists of design artifacts and a narrative. A design artifact is something that your group creates that represents your design, (such as a sketch, a mock-up, a prototype, or a screencast) or the process of creating it (such as a photo of a whiteboard brainstorm, notes from an interview, or sketches that you discarded). Since your design portfolio is electronic, any artifact that was originally in some other media (e.g. whiteboard, paper) needs to be captured in some electronic form. The narrative captures "the story behind the design" (to use Dorst's terminology), and is a single text document of between 1200 and 1500 words. Make sure to provide clear names for each of your artifacts, and refer to these by name in your narrative.

Artifact 2: Portfolio requirements 


\section{Artifacts from student portfolios}

The design brief during the winter 2010 term was "You will create a 'How-To' that moves students along the trajectory from novice (i.e. students who are in their first year at university) toward expert in using the campus library resources to get academic work done. In developing this how-to, each group will work with a librarian (i.e. a domain expert) on campus." To give a concrete sense of the student portfolios, I provide some of the themes that were addressed in them, illustrated by sample artifacts drawn from them. Students consented to the use of their artifacts in this paper.

\section{Learning from interaction with users}

One of the challenges in using milestone reports was that I did not believe students were getting frequent enough feedback from users, and they were not turning this feedback into design insights. But with the portfolios, students almost always provided clear evidence, not only that they had performed user inquiry and usability tests, but that they had learned useful things from them. Artifact 3 shows such an example from one of the student portfolios. Note the student artifact (i.e. the bulleted list), and the start of the narrative that summarizes and contextualizes the artifact.

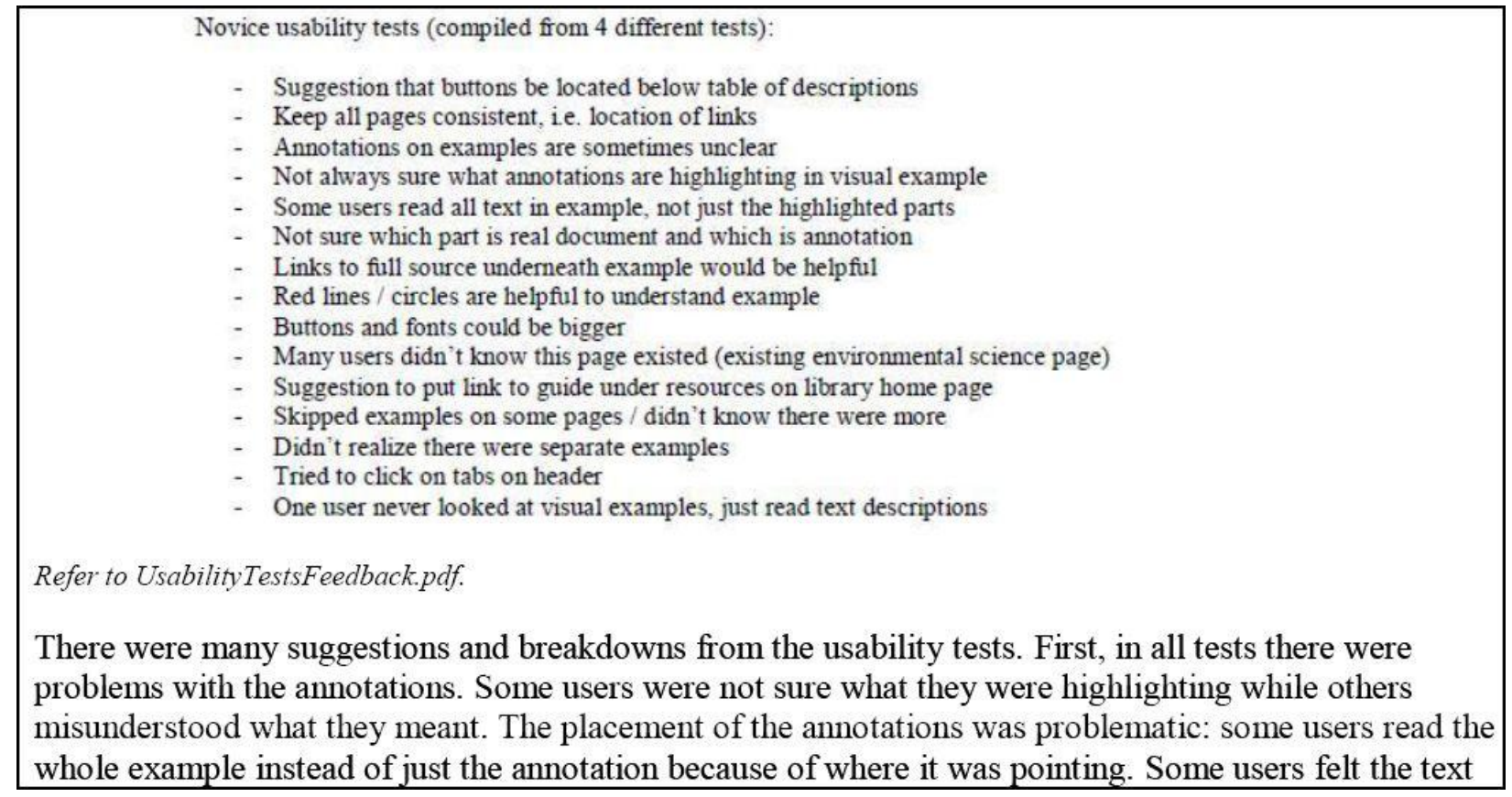

Artifact 3: Learning from interaction with users

\section{Design evolution}

The portfolios also made visible the evolution of student designs from the start to the end of the academic term. Artifact 4 consists of three artifacts from the final portfolio of a group that designed a website to help users navigate the physical resources in the library. The leftmost artifact is their initial sketch, the middle is a sketch of their design halfway through the term, and the rightmost is a screenshot of their final design. The narrative part of the portfolio (not shown) 
discussed how user studies, interaction with the domain expert, usability studies, and Jake's design critiques all contributed to the changes that they made from one design iteration to the next. By coupling artifacts with narrative, and tracing the design evolution across iterations, I could see in a comparative fashion not only the specific changes to the design, but the reasons that led students to make these changes.

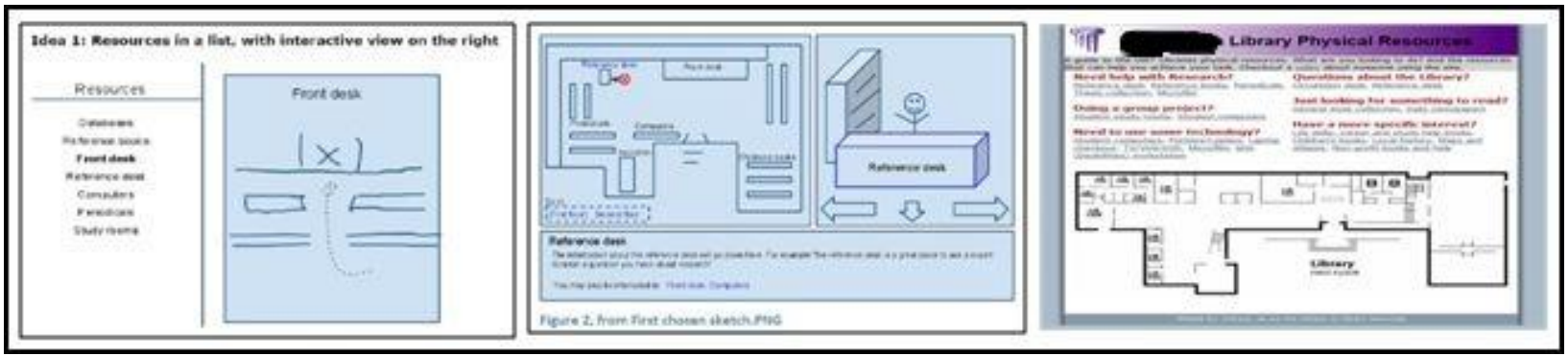

Artifact 4: Design evolution

\section{Impact of the industry fellow}

In working with an industry professional, I was curious about his impact on student learning. I could survey students about changes to motivation as a result of his participation, but I was curious if the industry fellow had a more direct impact on the designs that students created. Would students be receptive to his specific critiques of their designs, and would this lead them to make changes?

The portfolios made abundantly clear that the industry professional had considerable impact on most of the students. In their portfolio, one group wrote "according to Jake, 'buttons do things, links take you to places.' He suggested using links and getting rid of the buttons since the operation takes the user to another page."' Another group stated "Flash forward to the presentation of this click-through, when the design began to fall apart under the detailed scrutiny of the strongest two opinions in the class: our industry fellow from Google, and our professor." The most compelling example of impact is demonstrated in Artifact 5. The image at the bottom is a clip from a two minute critique that Jake did that he captured in a screencast and uploaded to Youtube. The narrative provides a bullet list of the specific comments that they gleaned from the critique. And the title of this portfolio section "This is His Day Job" and comment "seeing as how he does this for a living, we really paid attention to what he said" showed that students took his comments very seriously. 


\section{This is His Day Job}

Before we created a new mochup, we were able to get feedback on our current mochup from Jake. He had similar comments as users but als o several new in sights we had not thought of. Seeing as how he does this for a living, we really paid attention to what he said. Below is a screenshot of his screencast. Among other things, Jake's chief concem was the how "noisy" the firstpage was. He thought the font colors, size of the title, location of buttons, and the large amount of text was confusing. It made him unsure of where to click or go to. Here is a shortlist of his critiques:

- Take control of the page, tell the user why they should care

- Make title stronger

- Guide the user's eyes, "take them on a joumey"

- Keep pages consistent, i.e. buttons vs. links

- Annotations not clear

- Make difference between document and annotation clear

- Blur, magnify, or otherwise distinguish what is important for user to look at With all these suggestions, we decided for our next iteration to create our own web site instead of embedded content on the existing library page. This would enable us to control the pages and enable us to easily guide users to theright places.

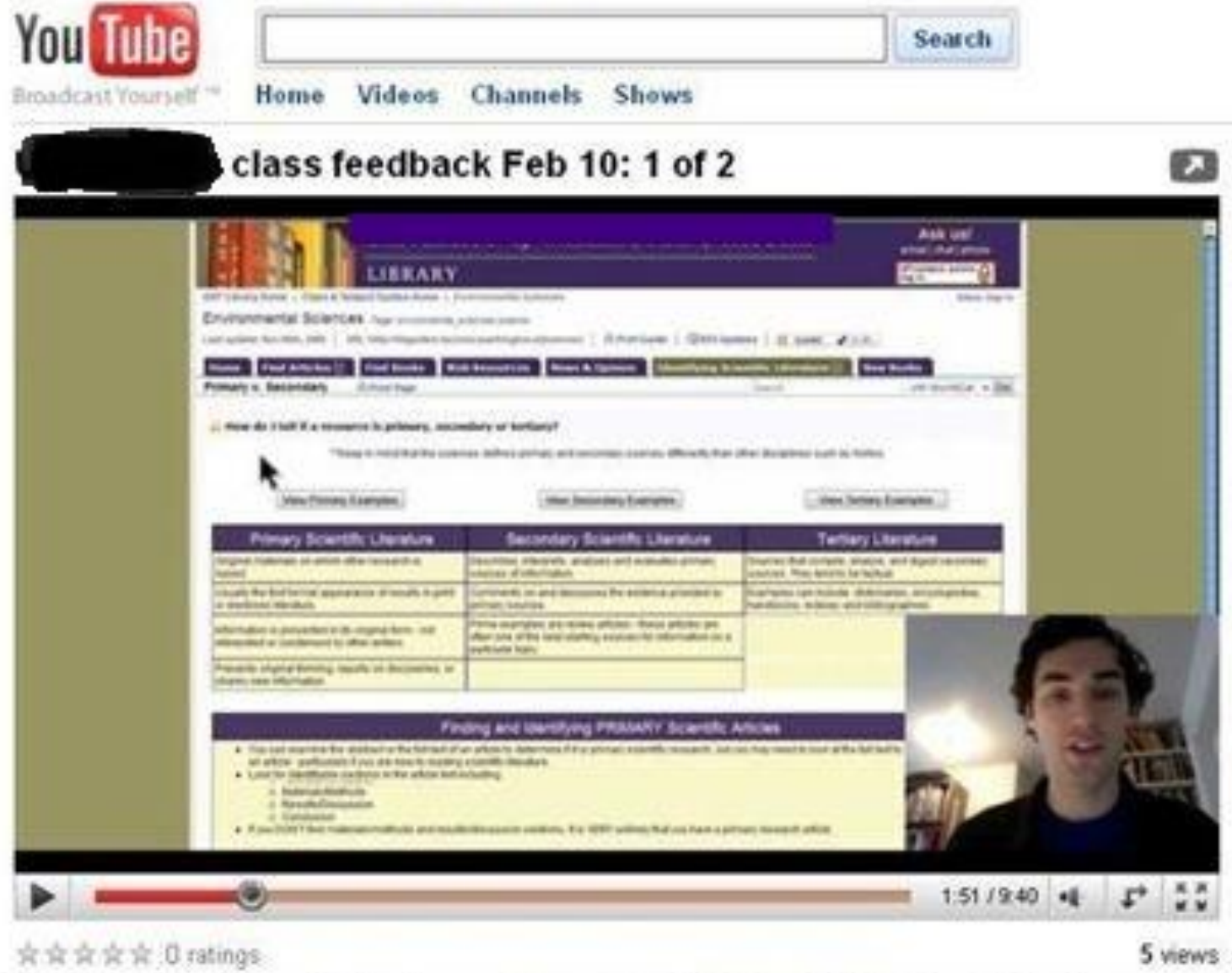

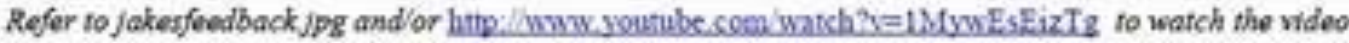

Artifact 5: Impact of industry fellow 


\section{Assessing portfolios}

I did not assess the portfolios in isolation, but used them along with the current design to determine how well students were achieving the two primary learning goals: that students recognize that they are not the user, and that they engage in iterative cycles of design exploration and refinement. The portfolio provided a compact and clear form in which I could see the presence of both the expert and novice users. It showed the extent to which the students were relying on their uninformed intuition or whether they were designing based on the feedback obtained from contextual inquiries and usability studies. The portfolios also made evident the evolution of student designs from one milestone to the next. This allowed me to distinguish between those groups who became locked into rigid design ideas early and were unwilling to change or abandon these in the face of novice and expert critique, and those groups willing to strike out in new directions, especially if things were clearly not working.

One other consideration that I used in assessing the portfolios concerned their status as stories. Ultimately, I asked myself if they had narrative coherence? Did they tell a story that accounted for their key design choices? Did the story make sense, or did it leave gaps or logical inconsistencies? And was there congruence between the artifacts and the narrative?

My final artifact is feedback that I provided to one of the groups on their portfolio. Although I make critical comments, this artifact demonstrates the way in which the portfolio form makes clear when something is missing, when the backstory is incomplete.

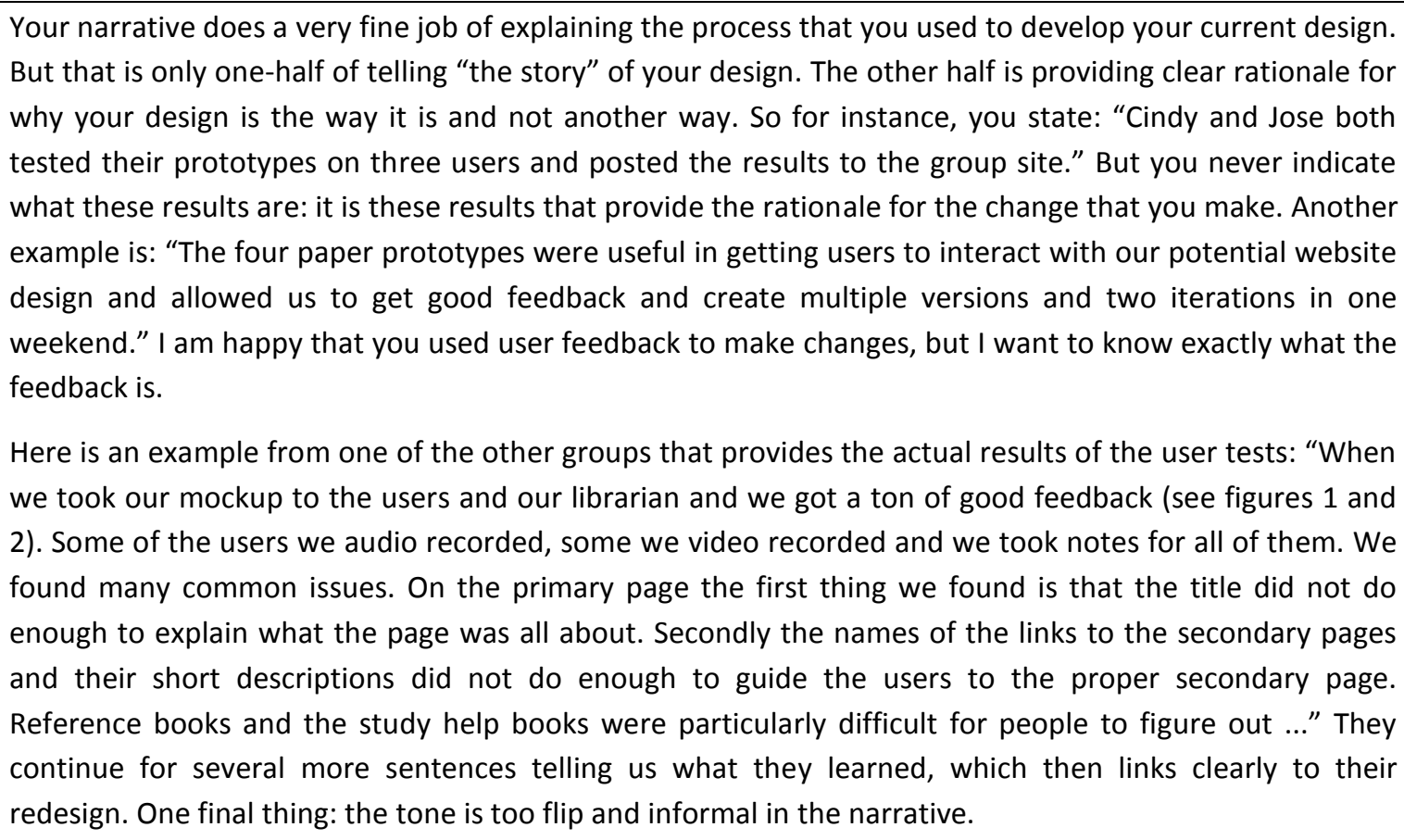

Artifact 6: Assessment feedback to students on portfolio

In summary, the portfolios worked well for assessing student work, in that they made the student learning visible, the design trajectory evident, and surfaced the underlying rationale for many of 
the key choices that students made. This is what Biggs ${ }^{1}$ refers to as constructive alignment between learning objectives and assessments, and he highlights that portfolios are particularly useful for achieving such constructive alignment.

\section{Other times, other places}

In this paper, I have described my use of portfolios in having students tell the backstory of their design project. The portfolios were fit to my purposes: fostering reflection on practice, reinforcing the notion of story that ran throughout the course, and serving to bridge the worlds of academia and professional practice.

What, if any of this work might transfer to other times and places, other classrooms and teachers? I underscore two points from the account here. The first is the importance of using story to organize learning. The psychologist Jerome Bruner believes that humans are both biologically and culturally constructed so as to use and interpret narrative as a structure for representing and comprehending human and social experience ${ }^{3}$. Certainly in the realm of design, telling envisioning stories of tools and devices not yet created, and backstories of how designs come to be the way that they are, are crucial practices of professional designers. Bruner additionally argues ${ }^{4}$ that stories of a certain sort have a dual nature. Our autobiographical narratives, the stories that we tell ourselves about who we are not only reflect our lived experience, but also shape it. Not only do we tell the lives we live, "we become the autobiographical narratives by which we 'tell about' our lives ${ }^{4}$." In telling the stories about their designs, particularly the backstory about how their designs came to be, students begin to be the people depicted in the stories that they tell themselves about who they are as engineers. That is, the backstories that the portfolios represent make explicit the designerly activities that students engage in over an extended period of time. In creating, perceiving, and presenting these stories to themselves and others, students come to see themselves as engineers, and in so doing become engineers.

The other point to underscore is how portfolios can serve as a common means for representing the backstory. Drawn from professional practice, portfolios require thoughtful selection of artifacts, and the interweaving of a narrative and artifact that provides a rationale for the important design choices within a fixed space constraint. Portfolios at the same time require their authors to reflect on the process of design while also making this process visible to others.

This is why I have chosen the portfolio form, rather than a more academic form, to tell this story. Selecting and presenting artifacts from my students' and my own use of portfolios, narrating the backstory of how I came to use them in my design course, and making this use visible to others, I

have tried to convey a sense of the possibilities that this form offers for representing learning and cultivating design practice. 


\section{Acknowledgements}

I extend sincere thanks to the The Helen Riaboff Whiteley Center of the Friday Harbor Laboratories of the University of Washington for providing the peaceful environment that enabled me to complete this manuscript.

\section{References Cited}

1. Biggs, John. What the student does: teaching for enhanced learning. Higher Education Research \& Development 18(1):57-75, 1999.

2. Brown, Ann, Doris Ash, Martha Rutherford, Kathryn Nakagawa, Ann Gordon, and Joseph Campione. Distributed expertise in the classroom. In Salomon, Gavriel (Ed.), Distributed cognitions: psychological and educational considerations. Cambridge University Press, 1993.

3. Bruner, Jerome. Acts of Meaning. Harvard University Press, 1990

4. Bruner, Jerome. Life as narrative. Social Research 54(1), 1987.

5. Buxton, Bill. Sketching User Experiences. Morgan Kaufmann, 2007.

6. Costantino, Patricia and Marie De Lorenzo. Developing a professional teaching portfolio : a guide for success. Allyn and Bacon, 2002.

7. DiMarco, John. Web portfolio design and applications. Idea Group Publishing, 2006.

8. Disciplinary Commons website. http://www.disciplinarycommons.org/. Accessed March 1, 2011.

9. Dorst, Kees. Understanding design: 150 reflections on being a designer. BIS Publishers, 2003.

10. Dumas, Joseph and Janice Redish. A Practical Guide to Usability Testing. Intellect Ltd, 1999.

11. Fincher, Sally and Josh Tenenberg. Warren's Question. ICER '07: The Third International Computing Education Research Workshop, Atlanta, Georgia, USA, 2007.

12. Interaction Design course homepage winter 2009, http://faculty.washington.edu/jtenenbg/courses/452/w09/. Accessed 2 December 2, 2010.

13. Lim, Youn, Erik Stolterman, and Josh Tenenberg. The anatomy of prototypes: Prototypes as filters, prototypes as manifestations of design ideas. ACM Transactions on Computer-Human Interaction, 15(2), 2008.

14. Linton, Harold. Portfolio design. W.W. Norton, 2003.

15. Myers, Debbie. The Graphic Designer's Guide To Portfolio Design. Wiley, 2005.

16. Norman, Donald and Stephen W. Draper. User Centered System Design: New Perspectives on Humancomputer Interaction. Lawrence Erlbaum Associates, 1986.

17. Selden, Peter. The Teaching Portfolio: A Practical Guide to Improved Performance and Promotion/Tenure Decisions, $4^{\text {th }}$ edition. Jossey-Bass, 2010.

18. Schön, Donald, The reflective practitioner. Basic Books, 1983.

19. Sullivan, William and Matthew S Rosin. A New Agenda for Higher Education: Shaping a Life of the Mind for Practice, Jossey-Bass, 2008.

20. Tenenberg, Josh. The ultimate guest speaker: a model for educator/practitioner collaboration. Eleventh Annual Northwestern Regional Conference Consortium for Computing Sciences in Colleges, Tacoma, WA, October 2009.

21. Tenenberg, Josh. Industry fellows: bringing professional practice into the classroom. In SIGCSE '10: Proceedings of the 41st SIGCSE Technical Symposium on Computer Science Education, Milwaukee, WI, USA, March 2010.

22. Industry Fellows website. http://depts.washington.edu/ifellows/. Accessed 2 December 2010.

23. Tenenberg, Josh and Sally Fincher. Opening the Door of the Computer Science Classroom: The Disciplinary Commons. SIGCSE '07: Proceedings of the 38th SIGCSE Technical Symposium on Computer Science Education, 2007.

24. Zubizarreta, John. The learning portfolio: reflective practice for improving student learning. Jossey-Bass, 2004. 
25. Beyer, Hugh and Karen Holtzblatt. Contextual design: defining customer-centered systems. Morgan Kaufmann, 1998.

26. Sharp, Helen, Yvonne Rogers, and Jenny Preece. Interaction design, 2nd edition. Wiley, 2007.

27. Tenenberg, Josh. Industry Fellows: A model for industry-academic collaboration in the engineering classroom. American Society of Engineering Education $118^{\text {th }}$ Annual Conference \&. Exposition.

Vancouver, Canada, June 2011. 